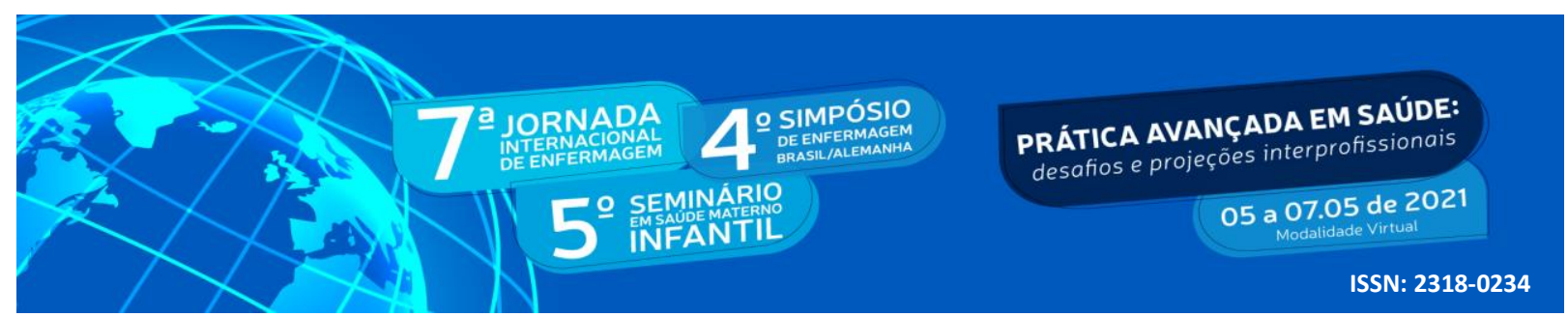

DOI: http://doi.org/10.48195/jie2021-020

\title{
O CUIDADO CENTRADO NA FAMÍLIA DO PREMATURO NO ÂMBITO DA UNIDADE DE TERAPIA INTENSIVA NEONATAL ${ }^{1}$
}

\author{
Camila Freitas Hausen²; Diúlia Calegari de Oliveira ${ }^{3}$; Francielle Brum dos Santos de \\ Siqueira ${ }^{4}$; Francielle Morais de Paula ${ }^{5}$; Leonardo Bigolin Jantsch ${ }^{6}$; Eliane Tatsch \\ Neves $^{7}$
}

\begin{abstract}
RESUMO
Objetivo: Analisar as características e tendências das produções científicas brasileiras acerca do Cuidado Centrado na Família(CCF) do recém-nascido prematuro em Unidade de Terapia Intensiva Neonatal(UTIN). Metodologia: Revisão narrativa da literatura, incluindo teses e dissertações nacionais. A busca dos dados foi realizada em janeiro de 2021, no Banco de Teses e Dissertações da Capes. Foram íncluidas no estudo seis produções. Resultados: Emergiram as implicações positivas do CCF para o prematuro e sua família no âmbito da UTIN, em especial aquelas relacionadas ao neurodesenvolvimento neonatal. Já os entraves, destaca-se os sentimentos parentais gerados durante a internação e a necessidade de adesão e capacitação da equipe multiprofisional. Conclusões: Concluiu-se que há escassez de publicações/estudos no ambito da pós-grduação nacional relacionadas a adesão e implantação do CCF pela equipe multiprofissional. Esses achados implicam na necessidade de maiores discussões temáticas acerca do CCF no contexto da terapia intensiva e criação de estratégias de implantação.
\end{abstract}

Palavras-chave: Recém-nascido prematuro; Unidade de terapia intensiva neonatal; Cuidado desenvolvimental; Cuidado centrado na família; Enfermagem.

\footnotetext{
ABSTRACT

Objective: Analyze the characteristics and trends of Brazilian scientific productions about FamilyCentered Care (FCC) of premature newborns in the Neonatal Intensive Care Unit (NICU). Methodology: Narrative literature review including national theses and dissertations. The search for the data was carried out in January 2021, at the Bank of Theses and Dissertations of Capes. Six productions were included in the study. Results: The positive implications of FCC for the premature and his family in the NICU have emerged, especially those related to neonatal neurodevelopment. As for the obstacles, parental feelings generated during hospitalization and the need for adherence and training of the

${ }^{1}$ Estudo de revisão narrativa da literatura, incluindo teses e dissertações nacionais. Oriundo de recorte de Trabalho de Conclusão de Curso de Pós-graduação de Enfermagem em Intensivismo Pediátrico e Neonatal.

${ }^{2}$ Enfermeira. Mestranda no Programa de Pós-graduação em Enfermagem (PPGENF) da Universidade Federal de Santa Maria (UFSM). camilafht@ @ hotmail.com

${ }^{3}$ Acadêmica do curso de Enfermagem da UFSM. E-mail: diuliacoliveira@gmail.com

${ }^{4}$ Enfermeira. Mestranda no PPGENF/UFSM. E-mail: francisbrum@gmail.com

${ }^{5}$ Enfermeira. Mestranda no PPGENF/UFSM. E-mail: fraanmdepaula@gmail.com

${ }^{6}$ Coorientador. Doutor Professor Adjunto no Departamento de Ciências da Saúde da UFSM, campus Palmeira das Missões. leo_jantsch@hotmail.com

${ }^{7}$ Orientadora. Doutora Professora Adjunta no Departamento de Enfermagem da UFSM. eliane.neves@ufsm.br
} 


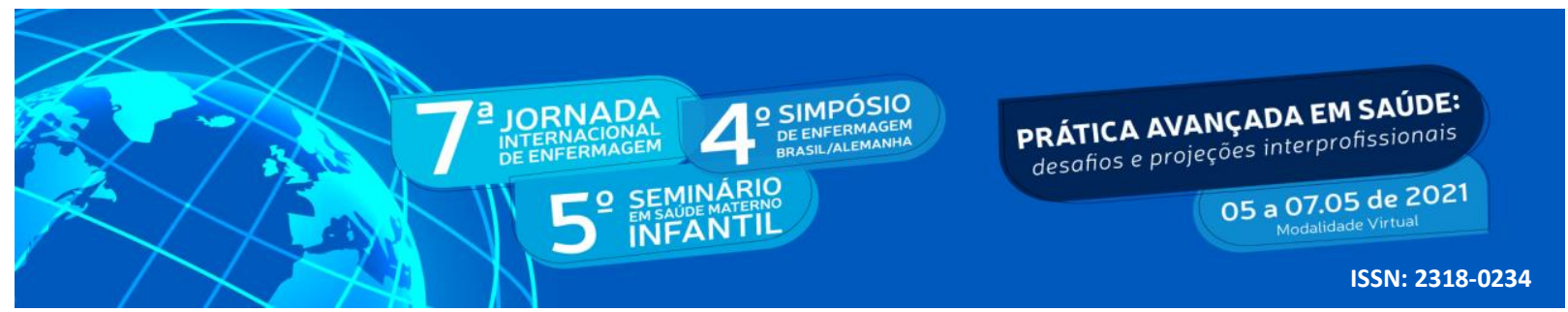

multiprofessional team stand out. Conclusions: The study demonstrated a scarcity of publications / studies in the context of national postgraduate studies related to the adhesion and implantation of the FCC by the multiprofessional team. These findings imply the need for further thematic discussions about the FCC in the context of intensive care and the creation of implantation strategies.

Key Words: Premature newborn; Neonatal intensive care unit; Developmental care; Family-centered care; Nursing.

\section{INTRODUÇÃO}

A expansão das Unidades de Terapia Intensiva Neonatal (UTIN) contribuíram para o aumento da sobrevida dos recém-nascidos pré-termo (RNPT) (SOUSA et al., 2017). No Brasil, em 2019, 315.831 dos nascimentos foram antes da 37 semana de gestação (BRASIL, 2019), sendo prematuridade a principal causa de internação em UTIN.

A imaturidade dos sistemas do RNPT o expõe a diversas complicações, associada as inúmeras intervenções para manutenção de sua estabilidade clínica, o que acaba resultando em condições ambientais de alta estimulação (CHAGAS et al., 2009). Tais fatores associados à prematuridade, podem se influenciar no padrão de desenvolvimento cerebral desses bebês (BRASIL, 2017; COUGHLIN; GIBBINS; HOATH, 2009), tornando-os mais suscetíveis à presença de eventos adversos e ao comprometimento neurodesenvolvimental (SOUSA et al.,2017). Nessa perspectiva surgiu o conceito do Cuidado Desenvolvimental, o qual é uma filosofia que visa reduzir os fatores estressores do ambiente e as taxas de morbidade infantil, por meio de ações simples como cuidados baseado no comportamento e estado evolutivo de cada bebê (COUGHLIN; GIBBINS; HOATH, 2009).

Atualmente, o conceito foi ampliado por Coughlin, Gibbins e Hoath (2009), que descreveram uma teoria a qual citam as cinco principais medidas para a operacionalização ideal do cuidado desenvolvimental em UTIN, sendo elas: o ambiente terapêutico; a redução, avaliação e gerenciamento do estresse e dor; proteção ao sono; cuidados com as atividades de vida diária e os cuidados centrados na família. O Cuidado Centrado na Família (CCF) é definido como um modelo de cuidar que reconhece a família como central e constante na vida da criança, sendo sua fonte primária de suporte (HOCKENBERRY; WILSON, 2014).

Destaca-se a importância da minimização de riscos por meio da realização do cuidado desenvolvimental, com destaque ao seu componente do CCF. Ainda, sabe-se o quão é necessário o aprofundamento e busca por conhecimentos nesta área. Neste contexto, buscou-se 


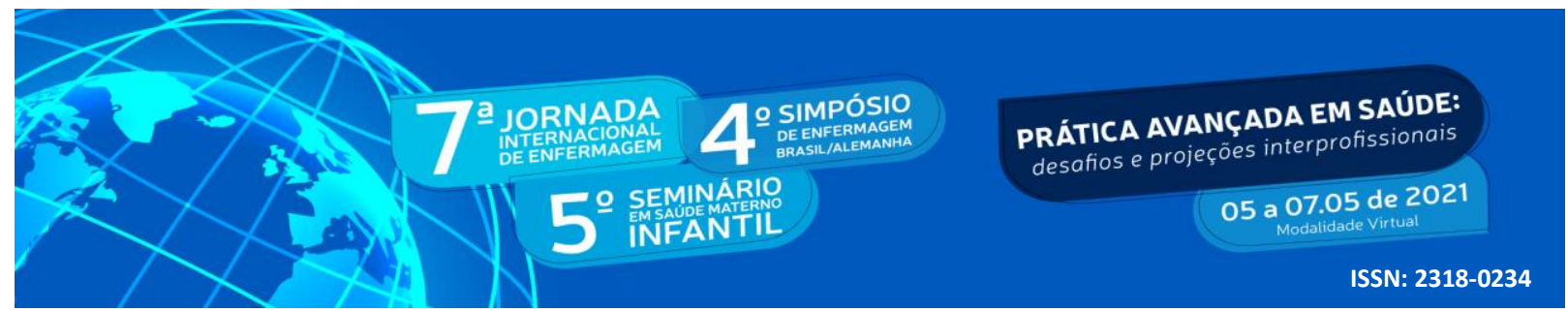

responder à questão de pesquisa: "O que tem sido produzido nos programas de pós-graduação brasileira referente à temática do cuidado centrado na família do prematuro, sob a perspectiva do referencial do desenvolvimental?".

\section{OBJETIVO}

Analisar as características e tendências das produções científicas brasileiras acerca do Cuidado Centrado na Família do recém-nascido prematuro no âmbito da Unidade de Terapia Intensiva Neonatal.

\section{METODOLOGIA}

Revisão narrativa da literatura por meio de busca realizada no Banco de Teses e Dissertações da Coordenação de Aperfeiçoamento de Pessoal de Nível Superior (CAPES), janeiro de 2021, buscando-se os termos "cuidado desenvolvimental" and "família", em todos os campos, resultando em 37 publicações

Os critérios de inclusão foram: teses e dissertações sobre a temática do Cuidado Centrado na Família (CCF), convergente com a filosofia do Cuidado Desenvolvimental (CD). Ainda, que os estudos contemplassem a temática da prematuridade e tivessem como cenário a UTIN. Os critérios de exclusão foram: estudos com resumo incompletos e/ou não disponível no banco de dados. Não foi realizado recorte temporal. A partir da busca foi realizada a leitura dos títulos e resumos, e após aplicação dos critérios houve a exclusão de: dez estudos por não serem da temática e 18 estudos excluídos por não respoderem a questão de pesquisa. Nove produções foram selecionadas para leitura na íntegra; posterior a leitura na íntegra dos trabalhos selecionados, três foram excluídas por não responderem a questão de pesquisa, restando assim seis estudos incluídos nesta revisão, os quais são caracterizados no Quadro 1. A análise dos dados foi realizada por meio da análise de conteúdo de Bardin, pautando-se nas recomendações e no referencial do Universo do Cuidado Desenvolvimental.

Quadro 1 - Teses e Dissertações selecionadas no banco de teses e dissertações da CAPES, sobre a temática do CCF em UTIN. Santa Maria, RS. 2021.

\begin{tabular}{|l|l|l|}
\hline \multicolumn{1}{|c|}{ Título/código } & \multicolumn{1}{|c|}{$\begin{array}{c}\text { Autor/ } \\
\text { Ano }\end{array}$} & \multicolumn{1}{c|}{ Tipo } \\
\hline Vivendo no método canguru: a tríade mãe-filho-família/ T1 & $\begin{array}{l}\text { Caetano, } \\
2004\end{array}$ & Tese \\
\hline
\end{tabular}




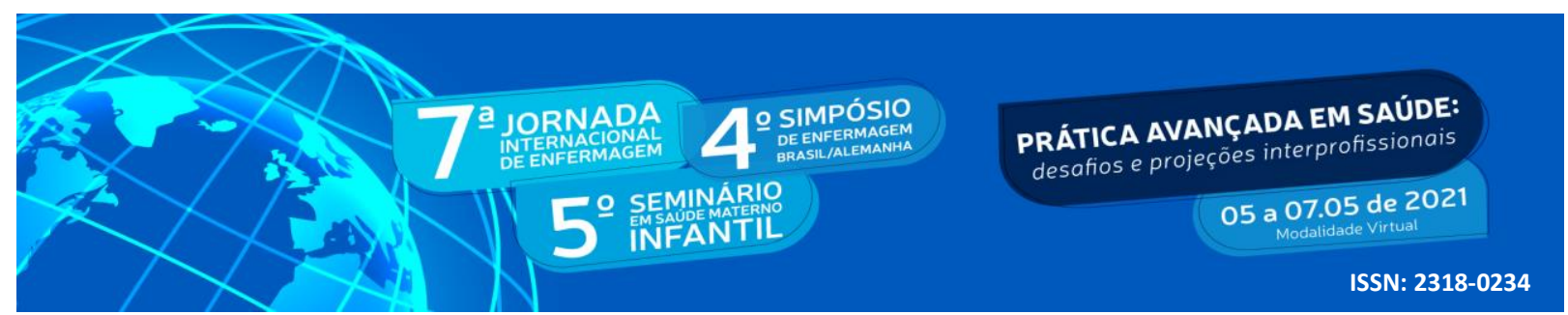

\begin{tabular}{|l|l|l|}
\hline $\begin{array}{l}\text { Implantação de um grupo de apoio à mãe acompanhante de recém- } \\
\text { nascido pré-termo e de baixo peso em um hospital amigo da criança na } \\
\text { cidade de Recife/PE. 2004/ T2 }\end{array}$ & $\begin{array}{l}\text { Vasconcelo } \\
\text { s, 2004 }\end{array}$ & Tese \\
\hline $\begin{array}{l}\text { A relação entre fatores maternos e a resposta à dor e ao estresse do } \\
\text { prematuro em posição canguru/ T3 }\end{array}$ & $\begin{array}{l}\text { Castral, } \\
2011\end{array}$ & Tese \\
\hline $\begin{array}{l}\text { Aprendendo e ensinando sobre os cuidados com o filho prematuro: a } \\
\text { vivência de mães em um programa de educação em saúde/ D1 }\end{array}$ & $\begin{array}{l}\text { Ferecini, } \\
2008\end{array}$ & Dissertação \\
\hline $\begin{array}{l}\text { O acolhimento materno no contexto da prematuridade em um Hospital } \\
\text { Amigo da Criança/ D2 }\end{array}$ & $\begin{array}{l}\text { Brazão, } \\
2014\end{array}$ & Dissertação \\
\hline $\begin{array}{l}\text { A vivência materna no contato pele a pele para alívio da dor em } \\
\text { prematuros submetidos ao teste do pezinho em unidade neonatal/ D3 }\end{array}$ & $\begin{array}{l}\text { Araújo, } \\
2015\end{array}$ & Dissertação \\
\hline
\end{tabular}

Fonte: elaborado pelos autores.

\section{RESULTADOS E DISCUSSÃO}

Quanto a caracterização das produções, três eram teses e três dissertações, a área de concentração e a região do estudo, todas estavam vinculadas a enfermagem e a região Sudeste do país, no estado de São Paulo. Quanto a abordagem metodológica a maioria (83\%) eram qualitativos e a população estudada, majoritariamente $(66,6 \%)$ foram as mães dos $\mathrm{RN}$ internados em UTIN.

Em relação a população (participantes dos estudos) os resultados (D1,T3,D2,D3) convergem com as demais produções da área em que a mãe é cuidadora principal em contextos de vulnerabilidade, como em internações em UTIN. Verifica-se a existência de um sentimento de sobrecarga, tendo em vista as múltiplas tarefas que as mães desempenham, a qual está associada ao significado atribuído à maternidade, ou seja, de que a "boa mãe" é responsável por "tudo". Essa ideia favorece a manutenção de um padrão tradicional de gênero e pouco estimula a participação do pai e irmãos no cuidado com os filhos (BENATTI et al., 2020).

Quanto à análise do conteúdo dos estudos, emergiram implicações positivas e implicações negativas que poderiam vir a influenciar sob um cuidado centrado na família no âmbito da UTIN, sob a percepção da família dos prematuros internados. Frente a isso, as produções estabelecidas foram divididas em duas categorias, as quais serão discutidas na sequência.

\section{Implicações positivas que podem favorecer cuidado centrado na família}

Os cuidados neuroprotetores e voltados ao desenvolvimento incluem várias estratégias, sendo uma delas os cuidados centrados na família, que podem potencializar conexões neurais, 


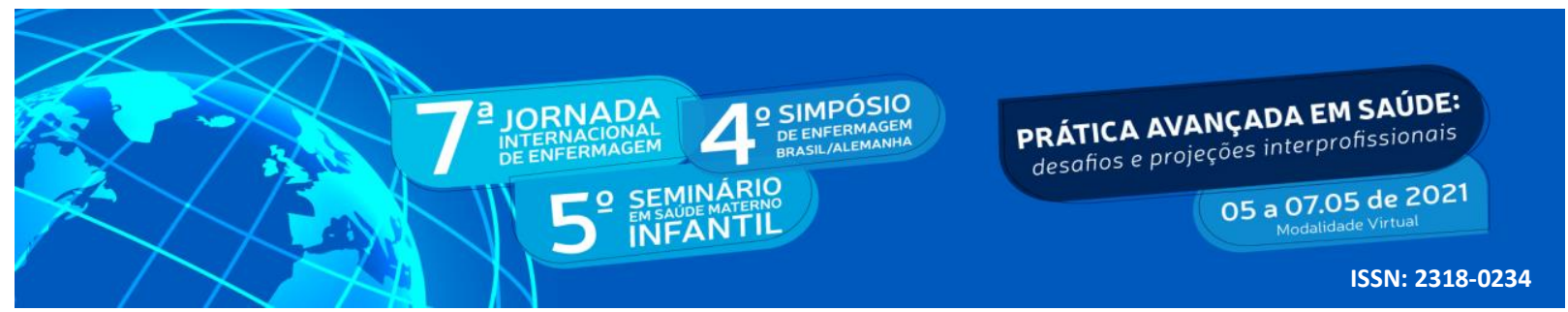

influenciando de maneira positiva para os prematuros internados em UTIN (MILETTE et al., 2017). O CCF, conforme o referencial do CD, destaca a importância do acolhimento e presença dos pais, incentivando o contato pele a pele e a serem os cuidadores primários do RN (GIBBINS et al., 2008).

A Norma de Atenção Humanizada do Recém-Nascido de Baixo Peso - Método Canguru é definida como um modelo para assistência perinatal brasileira, voltada para humanização da assistência aos bebês prematuros (BRASIL, 2017). O método é dividido em três etapas, e preconiza a participação da família. Destaca-se a segunda delas, no contexto da UTIN é uma parte essencial do método, onde a mãe e o seu filho permanecem juntos na Unidade de Cuidados Intermediários Canguru (UCINCa) e, gradativamente, preparam-se para a alta hospitalar (BRASIL, 2017). A participação no Método Canguru, bem como a inclusão da família na etapa dois (Unidade Canguru - UC) emergiu nos estudos selecionados para essa revisão ${ }^{(\mathrm{T} 1, \mathrm{D} 2)} \mathrm{e}$ foram considerados como pontos positivos para implementação e promoção do CCF.

Um dos estudos reforça a oportunidade proporcionada às mães pelo MC para aprender a cuidar do filho e de estar junto com ele, o que foi também potencializado pelo compartilhamento de experiências entre as mães da unidade e entre a família ${ }^{(\mathrm{T} 1)}$. A opção de participar do método, conforme resultados dos estudos ${ }^{(\mathrm{T} 1, \mathrm{D} 2)}$, deu-se, principalmente, devido à percepção da fragilidade do filho e o desejo de estar sempre perto. Relatam que a participação no MC aliviou os sentimentos de angústias frente a prematuridade, e de estarem mais próximo da alta $^{(\mathrm{D} 2)}$. Apontam-se outros benefícios trazidos pela participação no MC, como a diminuição de infecções hospitalares, aumento do ganho de peso diário, ausência de sintomas sépticos e redução na necessidade do oxigênio. A partir disso, ratifica-se o impacto positivo dosbenefícios, os quais são eficazes tanto para a regulação de aspectos físicos quanto psicológicos do RNPT, bem como seu potencial para a promoção do CCF (BANDEIRA et al., 2019).

Também, emergiu nos estudos o contato pele a pele por meio da posição canguru, a qual é estimulada pelo MC e pela filosofia do $\mathrm{CD}$, independente da etapa a qual o binômio está participando. Um dos estudos selecionados ${ }^{(\mathrm{T} 3)}$ abordou a temática visando investigar a associação entre os fatores maternos e a resposta à dor prematuros. Destaca-se que para além da redução da dor neonatal, percebe-se manifestações da promoção de vínculo entre mãe e RN, promovidos pela posição, Quando os bebês expressavam algum sinal de dor e/ou estresse, as 


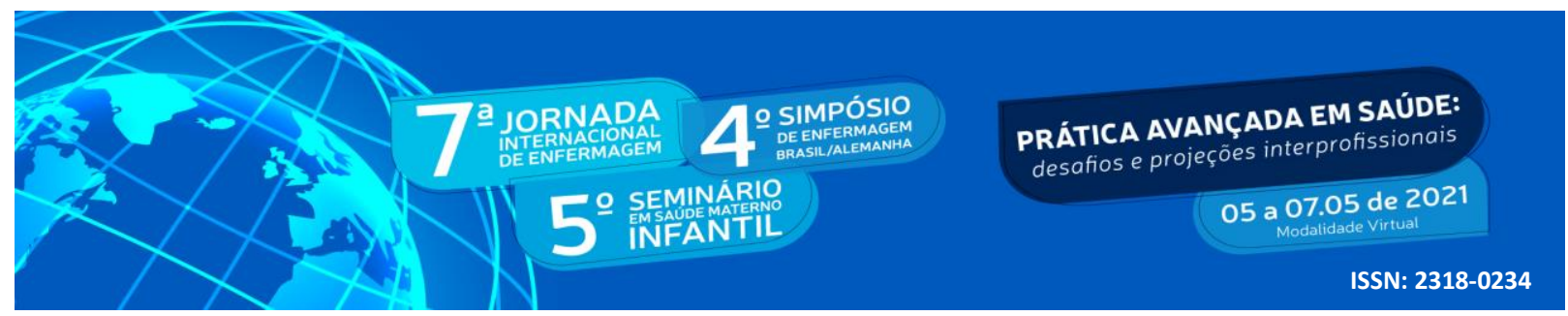

mães tornaram-se mais responsivas,aproximaram-se do bebê pelo abaixamento do tronco e cabeça e apresentaram vocalização (como sons arrulhos e tranquilizantes) ${ }^{(\mathrm{T} 3)}$.

Segundo Silva \& Braga (2019), o vínculo entre mãe-bebê, exerce função crucial no desenvolvimento biopsicoafetivo seguro e saudável, capaz de afetar todas as fases, desde o nascimento até a fase adulta. Pode ser demonstrado com toques, sons, massagens terapêuticas, ofurôs, colo, amamentação, entre muitos outros, com o objetivo principal de desenvolver e estimular o desenvolvimento do bebê (OLIVEIRA et al., 2019).

Ainda, outros estudos ${ }^{(\mathrm{D} 3, \mathrm{D} 2)}$ abordam mais benefícios percebidos pelas mães ao utilizarem a posição, como: promoção de prazer, tranquilidade ao bebê, maior inserção da mãe nos cuidados do filho, resgate do papel da maternidade, incentivo as outras mães a realizarem a posição, redução de estresse e favorecimento a estabilidade fisiológica do RN, por o colo e a UC tentarem assemelhar-se ao ambiente uterino.

Outros pontos positivos que destacamos para a promoção do CCF foi a participação

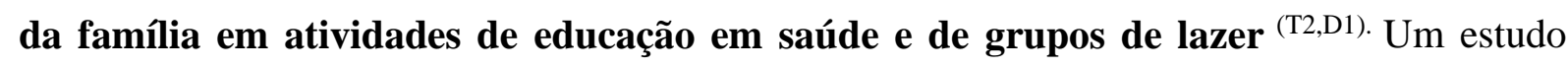
incluído ${ }^{(\text {T2) }}$ descreveu a experiência de implantação de um grupo de apoio às mães de RNPT e a iniciativa possibilitou que as mães pudessem ser ouvidas, compartilhassem seus medos, dúvidas e necessidades,tornando o hospital um espaço de descontração. Ainda, os grupos propuseram ações de relaxamento e entretenimento, minimizando assim as sensações negativas de tristeza e solidão. Nesse contexto, as saídas do ambiente hospitalar para passeios, bem como as atividades manuais e jogos coletivos, colaboraram também para a humanização do cuidado $^{(\mathrm{T} 1)}$.

Ainda, atividades em grupos estimularam a aquisição e estreitamento de vínculos afetivos entre as mães, conforme os relatos trazidos ${ }^{(\mathrm{T} 2)}$, foram citadas como benefícios a empatia entre as mulheres, o aumento da produção do leite materno, a aquisição de novas amizades, a troca de experiências, a promoção ao acolhimento e ao compartilhamento de palavras de confiança e conselhos. Resultados semelhantes sobre a formação da rede de apoio entre mães e a descontração por meio de técnicas de relaxamento (utilização de técnicas musicais e de alongamento) também foram evidenciados no estudo de Ferenci ${ }^{(\mathrm{D} 1)}$.

Quanto à participação nas atividades de educação em saúde, um dos estudos ${ }^{(\mathrm{D} 1)}$ verificou que o aprendizado por meio do programa foi efetivo, por meio da melhora dos scores 


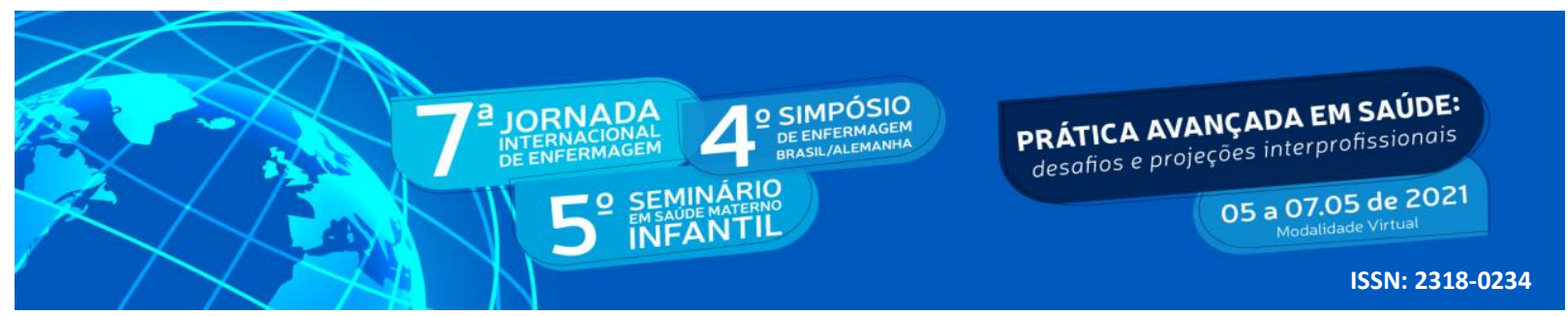

de pré e pós teste. Destaca-se a metodologia de aprendizagem participativa utilizada nesse programa, a qual permitiu que as mães se expressassem com liberdade. Conforme os relatos, a atividade possui como diferencial a metodologia descontraída e criativa, fugindo das orientações tradicionalmente "passadas" pela equipe de maneira repetitiva e monótona ${ }^{(D 1)}$.

Destaca-se que perante os referenciais abordados neste trabalho, compete a equipe multiprofissional a educação em saúde e a orientação aos pais e familiares quanto às habilidades necessárias para cuidar de seu filho prematuro, bem como fornecer apoio psicossocial às famílias. Essas abordagens, devem ser realizados em forma de convite a família, de maneira culturalmente sensível e quando os mesmo sentirem-se confiantes para o desenvolvimento de tais atividades (ALTIMIER et al., 2016; COUGHLIN; GIBBINS; HOATH, 2009). Estratégias como essas, de apoio, escuta, lazer e educação, podem e devem ser utilizadas pelos profissionais de saúde atuantes com os familiares de UTIN, consolidando a educação em saúde e humanização no contexto hospitalar.

\section{Dificuldades e limitações para implantação do cuidado centrado na família.}

Das dificuldades enfrentadas pelas famílias que podem contribuir para não implantação do cuidado centrado na família podem ser o surgimento de sentimentos negativos durante a internação $^{(\mathrm{D} 2, \mathrm{~T} 1)}$. Os quais iniciam desde o impacto de uma gestação de risco, com a separação súbita entre mãe e bebê logo após o nascimento e mantém-se durante a internação do RN na $\mathrm{UTIN}^{(\mathrm{D} 2, \mathrm{~T} 1)}$.

Os estudos trazem como uma dificuldade a surpresa das famílias em lidar com o nascimento prematuro. A identificação de um filho prematuro, por vezes frágil, o qual não pode ser tocado ou colocado em seus colos imediatamente, traz sentimento de tensão pelos pais ${ }^{(\mathrm{T} 1)}$. As famílias chocam-se ao presenciar o ambiente da UTIN, com tubos e aparelhos os quais seu bebê faz uso. Ao realizar essa comparação com os demais filhos e/ou a outros bebês saudáveis pode surgir sentimentos de frustração, pois esperava-se um filho saudável ${ }^{(\mathrm{T} 1, \mathrm{D} 2)}$. Há também a incerteza da sobrevida e/ou da presença de morbidades futuras, o que leva ao sentimentos de sofrimento, tristeza, angústia e estresse ${ }^{(\mathrm{D} 2)}$.

Dessa forma, as famílias sofrem com o contraste da idealização da criança saudável em comparação com a criança hospitalizada, o que gera grande impacto. A UTI configura-se como 


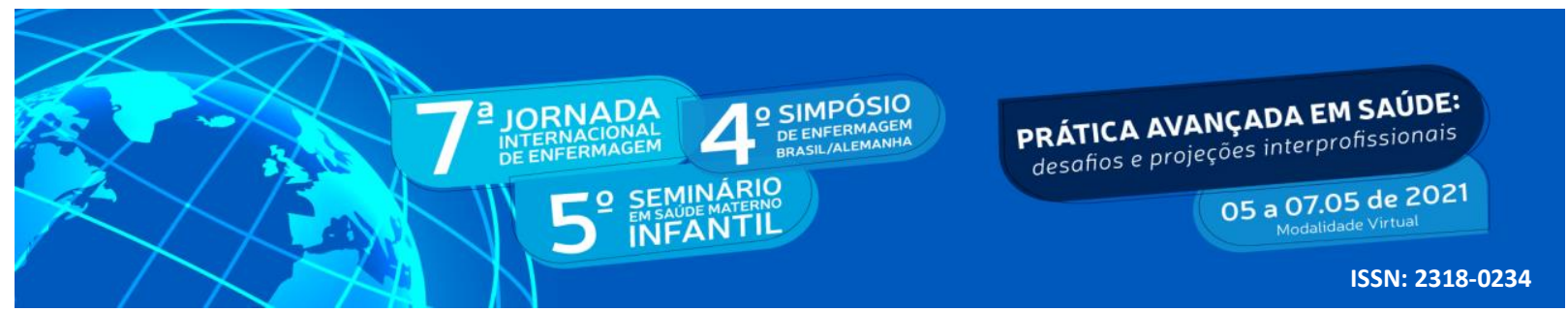

um local que desencadeia situações e vivências contraditórias de separação/apego, tristeza/alegria, além do sentimento de futuro incerto para a criança (PERLIN et al., 2011). Desta maneira, a equipe multiprofissional deve buscar tornar as visitas menos traumáticas para os pais e tentar reduzir o impacto do ambiente, através de um diálogo aberto e franco (FERREIRA; SOUZA, 2010).

Ao ter um filho internado na UTIN e ao ter a oportunidade de participar da segunda fase do método canguru, na Unidade Canguru, principalmente as mães ainda perpassam por sentimentos indecisão, ambivalência e sentem-se divididas devido a demanda dupla entre o ambiente hospitalar e o domicílio ${ }^{(\mathrm{T} 1, \mathrm{~T} 2)}$. A família tenta manter o equilíbrio entre as duas dimensões tão diferentes, e nos estudos relatam que ambos têm valor igual, porém referem dificuldades ao vivenciar e submeter-se a rotina hospitalar. São dificuldades citadas ao vivenciar a experiência de internação, tanto na UTIN e/ou ao participar da Unidade Canguru: a cobrança do marido em relação a vida de casal, o cansaço das idas frequentes ao hospital, o afastamento da família e da vida social e pessoal, saudade da família, principalmente de membros mais próximos, como marido, mãe, pai e irmãos, e principlamente o fato de ter outro(os) filho (os) que também demandam seus cuidados (D2, T1,T2).

Algumas das dificuldades as quais emergiram foram impostas pelos profissionais e pelas instituições e foram classificadas como dificuldades para a promoção do CCF (T2,T1,D2). Nos grupos de escutas com os familiares, foram recebidas queixas de condutas de determinados membros da equipe de saúde em relação a falta de delicadeza ao realizar o manejo com os bebês, dificuldades no relacionamento interpessoal entre equipe e família, como o não esclarecimento de dúvidas, falta de orientações e a resistência da equipe para presença e visitas dos familiares (T1,T2, D2).

Ainda, a respeito das instituições percebeu-se nas falas algumas regras impostas que por vezes faziam as mães sentirem-se aprisionadas na UC, por não poderem sair do ambiente hospitalar e pela limitação de espaço na unidade ${ }^{(\mathrm{T} 2)}$. O que demonstra que por mais que as instituições preguem uma prática voltada à humanização, como a iniciativa hospital amigo da criança, percebe-se que nem sempre as ações são realmente estabelecidas, e o foco permanece em normas e rotinas "institucionalizadas", no modelo biomédico e ao cuidado centrado apenas na criança doente, sem olhar ampliado a família ${ }^{(D 2)}$. 


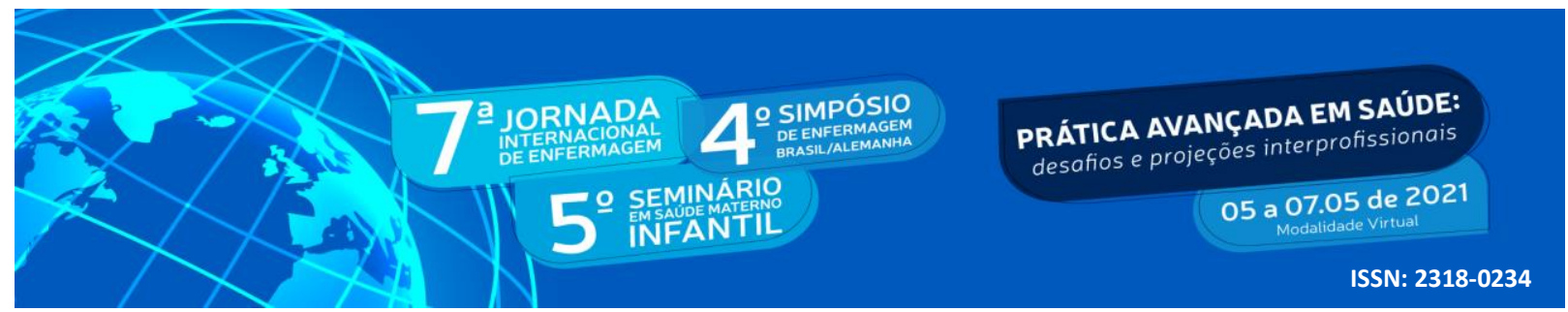

Frente a esses resultados, sugerem-se estratégias, baseadas na filosofia do CD, que podem contribuir para modificação e extinção de práticas inadequadas no âmbito da UTIN. Destaca-se que o referencial do UCD é formado com base na educação da equipe (GIBBINS, 2008), sugerindo-se assim como estratégias: o levantamento de diagnóstico situacional das unidades (com objetivo de identificar onde estão as fragilidades), a educação permanente com as equipes e maior envolvimento da gestão hospitalar.

\section{CONCLUSÃO}

Concluiu-se que há escassez de publicações relacionadas à equipe multiprofissional e com os demais membros da família visto que a mãe é personagem protagonista no cuidado e nos objetos dos estudos. Outros membros familiares são coadjuvantes nos cuidados e estudos. A partir da óptica da filosofia do CD e com o intuito de implementar e promover o CCF, discutiu-se as implicações positivas e os desafios para sua adesão no contexto da terapia intensiva neonatal. Quanto às implicações positivas, além do $\mathrm{CD}$, também condizem com as políticas públicas vigentes do MC e da política de Humanização. Em relação às dificuldades de implantação surgem os sentimentos negativos da familia e a maior necessidade de educação permanente com as equipes de saúde para sugere-se à sua redução através da educação permanente nos serviços partindo das necessidades de cada realidade e maior envolvimento da gestão hospitalar, buscando assim o aprimoramento do cuidado aos RNPT internados em UTIN.

\section{REFERÊNCIAS}

ALTIMIER, L., et al. The Neonatal Integrative Developmental Care Model: Advanced Clinical Applications of the Seven Core Measures for Neuroprotective Family-centered Developmental Care. Newborn \& Infant Nursing Reviews, v. 16, n. 4, p. 230-244, dec. 2016. DOI: https://doi.org/10.1053/j.nainr.2016.09.030

BANDEIRA, C.C.C., et al. Os benefícios do método canguru em recém-nascidos pré-termo: relato de experiência. Boletim informativo Unimotrisaúde em Sociogerontologia - BIUS outubro, v. 13, n. 7, out. 2019. Disponível em: < https://periodicos.ufam.edu.br/index.php/BIUS/article/view/6496>. Acesso em: 10 março 2021.

BENATTI, A.P.; PEREIRA, C.R.R.; DOS SANTOS, D.C.M.; PAIVA, I.L. A maternidade em contextos de vulnerabilidade social: papéis e significados atribuídos por pais e mães. Rev. Interação em Psicol, Curitiba/PR, v. 24, n. 2, p. 1-12. 2020. Disponível em: <https://revistas.ufpr.br/psicologia/article/view/59856/41441>. Acesso em: 03 março 2021. 


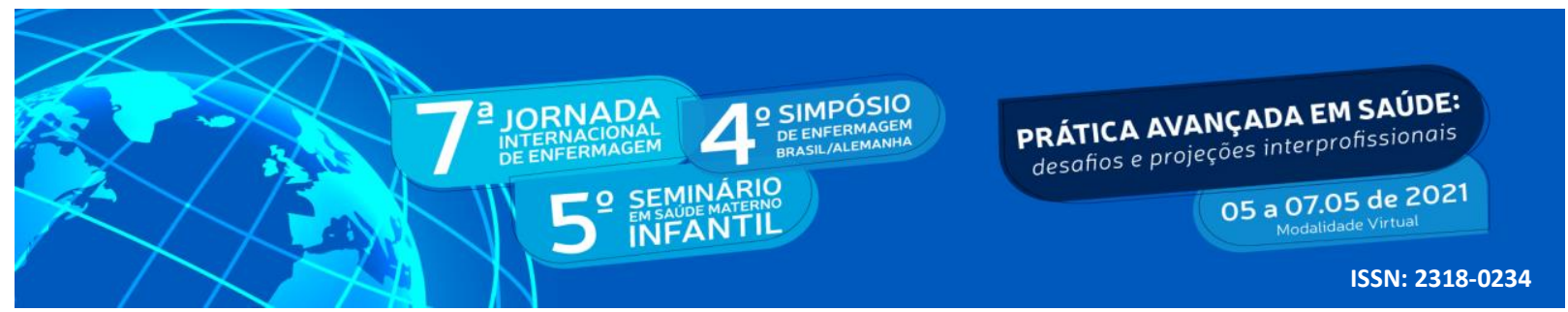

BRASIL. Ministério da Saúde. DATASUS: Nascimentos por resid. mãe por duração de gestação. 2019.

Disponível

em: $<$ http://tabnet.datasus.gov.br/cgi/tabcgi.exe?sinasc/cnv/nvuf.def>. Acesso em: 03 março 2021.

BRASIL. Ministério da Saúde. Secretaria de Atenção à Saúde. Departamento de Ações Programáticas Estratégicas. Atenção à saúde do recém-nascido Método Canguru: manual técnico. $\quad 3^{\mathrm{a}}$ ed. Brasília: Ministério da Saúde, 2017. Disponível em: < https://bvsms.saude.gov.br/bvs/publicacoes/atencao_humanizada_metodo_canguru_manual_3 ed.pdf>. Acesso em: 03 março 2021.

CHAGAS, R.I.A.; VENTURA, C.M.U.; LEMOS, G.M.J.; SANTOS, D.F.M.; SILVA, J.J. Análise dos fatores obstétricos, socioeconômicos e comportamentais que determinam a frequência de recém-nascidos pré-termos em UTI neonatal. Revista da Sociedade Brasileira de Enfermeiros Pediatras, São Paulo, v. 9, n. 1, p. 7-11. 2009. DOI: https://doi.org/10.31508/1676-3793200900002

COUGHLIN, M.; GIBBINS, S.; HOATH, S. Core measures for developmentally care in neonatal intensive care units: theory, precedence and practice. Journal of Advanced Nursing, v. 65, n. 10, p.2239-2248, 2009.

FERREIRA, S.D.; SOUZA, K.M.O. Assistência humanizada em UTI neonatal: os sentidos e as limitações identificadas pelos profissionais de saúde. Ciência \& Saúde Coletiva, Rio de Janeiro, v. 15, n. 2, p. 471-480. 2010. Disponível em:< https://www.scielosp.org/pdf/csc/2010.v15n2/471-480/pt>. Acesso em: 10 março 2021.

GIBBINS, S., et al. The Universe of Developmental Care A New Conceptual Model for Application in the Neonatal Intensive Care Units. Advances in Neonatal Care, v. 8, n. 3, p. 141-147, jun. 2008. DOI: 10.1097 / 01.ANC.0000324337.01970.76

HOCKENBERRY, M.J.; WILSON, D. Wong: fundamentos de enfermagem pediátrica. 9 Ed. 2014. p.509.

MILETTE I., et al. Guidelines for the Institutional Implementation of Developmental Neuroprotective Care in the Neonatal Intensive Care Unit. Part A: Background and Rationale. A Joint Position Statement From the CANN, CAPWHN, NANN, and COINN. Can J Nurs Res, v. 49, n. 2, p. 46-62, 2017.

OLIVEIRA, P.R., et al. Projeto de Extensão "Mãos Amorosas" a importância de nutrir a pele dos bebês com amor por meio do toque. Revista Panorâmica, v. 28, 2019. Disponível em:<http://oca.ufmt.br/revista/index.php/revistapanoramica/article/viewFile/1083/19192282>. Acesso em: 10 março 2021.

PERLIN, D.A., et al. A criança na unidade de terapia intensiva neonatal: impacto da primeira visita da mãe. Rev Gaúcha Enferm, Porto Alegre/RS, v. 32, n. 3, p. 458-64. 2011. Disponível em: < https://www.scielo.br/pdf/rgenf/v32n3/04.pdf >. Acesso em: 10 março 2021.

SILVA, B.A.A.; BRAGA, L.P. Fatores promotores do vínculo mãe-bebê no puerpério imediato hospitalar: uma revisão integrativa. Rev. SBPH, Rio de Janeiro, v. 22, n. 1, jun-dez 2019. Disponível em: $<$ http://pepsic.bvsalud.org/pdf/rsbph/v22n1/v22n1a14.pdf $>$. Acesso em: 10 março 2021.

SOUSA, D.S.; JÚNIOR, A.S.S.; SANTOS, A.D.R.; MELO, E.V.; LIMA, S.O.; ALMEIDASANTOS, M.A. et al. Morbidity in extreme low birth weight newborns hospitalized in a high risk public maternity. Rev. Bras. Saúde Mater. Infant, Recife, v. 17, n. 1, p. 139-147, janmarço 2017. DOI: https://doi.org/10.1590/1806-93042017000100008 